\title{
Micro and Macro Levels of Translation Pedagogy: A Study on the Components of Translation Competence and the Ways to Develop It in Translation Courses
}

\author{
Abdollah Karimzadeh \\ Universities of Tübingen (Germany) and Bergamo (Italy) \\ E-mail: abdollah.karimzadeh@gmail.com
}

Ebrahim Samani (Corresponding author)

Dep. of English Language and Humanities, Universiti Putra Malaysia 43400, Serdang, Selangor, Malaysia

Tel: 60-14-716-9363 E-mail: ibrahim.samani@gmail.com

\section{Reza Vaseghi}

Dep. of English Language and Humanities, Universiti Putra Malaysia 43400, Serdang, Selangor, Malaysia

Tel: 60-11-1532-5810_E-mail: r.vaseghi85@gmail.com

\section{Seyed Ali Rezvani Kalajahi}

Dep. of English Language and Humanities, Universiti Putra Malaysia 43400, Serdang, Selangor, Malaysia

Tel: 60-12-256-6070 E-mail: ali.rezvani85@gmail.com

$\begin{array}{lr}\text { Received: April 19, } 2015 & \text { Accepted: May 2, } 2015 \quad \text { Published: May 2, } 2015 \\ \text { doi:10.5296/jse.v5i2.7465 } & \text { URL: http://dx.doi.org/10.5296/jse.v5i2.7465 }\end{array}$

\begin{abstract}
Micro level refers to those translation techniques which are applied for short textual segments and are usually of a prescriptive nature. In the other hand, the macro level refers to translation strategies as well as external factors that influence the decisions made by a translator and are of a descriptive nature.
\end{abstract}




\section{Macrothink}

Journal of Studies in Education

ISSN 2162-6952

2015, Vol. 5, No. 2

The current paper is aimed at examining the components of translation competence and the ways to develop it in the translation courses. On this basis, the concept of translation competence and its components have been analyzed and various classifications made by translation scholars of translation errors and problems and conceptual tools to describe and teach them have been presented.

Then, the external factors influencing translations and their manifestation in translation theories including Scopus theory by Vermeer, Holz-Mantari's translatorial action, Appiah's thick translation and in general, the poststructuralist and functionalist approaches to translation and the ways to teach them as well as the reasons for the shift of theories from source- orientation to target orientation and its pedagogical implications for translation courses have been investigated.

Keywords: Micro level, Macro level, Translation competence, Translation techniques, Translation strategies, Translation errors, Problems of translation, Translation education 


\section{Introduction}

A review of the literature indicates that the translation pedagogy involves both micro and macro levels, such that these two levels result in translation competence. Micro level which is linguistic-oriented often requires formal equivalence between source and the target text (Palumbo, 2009, p.123). On the other hand, macro-level which is functionalist sees translation as an act of communication that includes not only linguistic factors but also cultural, social, and historical factors (Palumbo, 2009, p.50)

Halverson (1997) considers these two general approaches as dominant paradigms in Translation Studies. The first approach, which was dominant till the 1970s saw translation as a mere act of linguistic decoding and encoding regardless of the specific socio-cultural context of the target texts, (Palumbo, 2009, p.123). In other words, its emphasis was merely on the linguistic dimension of translation and establishing a formal equivalence (syntactic, lexical and stylistic) between source and target texts. On the other hand, the second approach emphasizes the communicative dimension of translation in a bid to release the translation from the formalist approach (Palumbo, pp., 50, 20). Linguistic Approaches are "source-oriented", while the cultural approaches are function-oriented and target-oriented." Models and theories that are related to the functionalist approaches include Vermeer's Skopos theory and Holz-Mantari's translatorial action which were introduced during the late 1970s and early 1980s. Snell Hornby (2006) considers these theories as a part of cultural turn that happened in Translation Studies. Historically speaking, these approaches were proposed in reaction to the linguistic approaches that ignored extratextual factors. Linguistic theories are mostly concerned with the classification of translation shifts and transpositions and analysis of errors and their causes (Palumbo, p.50).

Functionalists look at translation through the lenses of Cultural Studies and pay attention to socio-cultural and historical contexts in which translations are produced (Palumbo, 2009, p. 30). They specifically pay attention to the values affecting the decisions made by translators (specifically the decisions of ideological, political and moral nature). For example, proponents of post-colonial theories of translation emphasize "hegemonic" structures in translation. That is, what happens when translations are done between dominant and dominated cultures (Robinson, 1997a, as cited in Palumbo, 2009). Furthermore, translation scholars interested in feminist theories try to expose phallocentric discourse of translation theories (for example, free translation has been described as unfaithful beauties and this description according to them strengthens the stereotype that beautiful women are unfaithful (Palumbo, 2009, p.52). They try to explore the way translations are influenced by culturally-constructed gender stereotypes. For example, how does gendered attitude contribute to identity construction of translators in the translated texts? Accordingly, women translators resort to the technique of overt translation and through writing forewords, annotations, or footnotes, establish their identity as a female (Palumbo, p. 52).

These examples are provided to show the extent of translation theories and levels the knowledge into which constitutes part of translation competence. Undoubtedly, the theoretical background of translation trainees is closely related to the quality of their 
translations. Having expounded the micro and macro levels of translation, the current paper attempts to analyze translation competence and the ways to foster them in translation trainees and in translation courses.

\section{The concept of translation competence}

Translation competence is defined as a set of knowledge, skills, and attitudes that enable a person to translate from one language to the other (Palumbo, 2009, p.21). Previously, these abilities were considered to be linguistic competence and no distinction was made between the competence of professional translators and that of the bilinguals, who had not undergone any training in translation, but recently translational competence of professional translators has caught the attention of translation scholars and the competence of untrained bilinguals has been viewed with suspicion.

Harris (1977, p.99) refers to translations that untrained bilinguals make as "natural translation." This kind of translation is viewed from two different perspectives. Harris assumes centrality for natural translation in Translation Studies, while Kring (1986) completely rejects it (Palumbo, 2009, p.96). Myriad other studies (Schaffner \& Adab, 2000; PACTE, 2005) have examined either how translation competence is generated or how translation trainees can develop it.

There exists no consensus yet on a unanimous definition of translation competence. Pym (2003, pp., 481-492) has identified four orientations out of the different models proposed for translation competence including: 1. translation competence as the output of all linguistic competences (competence in both source and target languages) which, according to him, is a traditional view. 2. Competence as no competence. In line with Chomsky, Pym (2003, p.284), points out that performance should not be mistaken with competence. On this basis, we would better use such concepts as "skill," "strategy," and "expertise" and so on instead. 3. Competence as multiple skills: (Pym points out that the list of these skills can be endless. So, it would be of no use from both theoretical and practical perspectives). 4. Competence as a super competence that is the competence which is restricted merely to translation and does not define anything else. Pym (2003, p.489) personally prefers the reductionist concept of competence and define it as:

"The ability to produce more than a target text (TT 1, TT 2, TT 3, TT 4 ...) for a single source text and at the same time the ability to choose one of them with justification and more confidence".

\section{The concept of translational behavior}

Some translation scholars see translation as a normative behavior that can be systematically oriented by behavioral psychology (Touri, 1999, p.21). Following Bourdieu, a French sociologist who had introduced the concept of habitus for the activists and agents of a specific field, Daniel Simeoni (1998, p.32 ) has introduced the concept of "translator's habitus" as thought and behavior patterns specific to translators, arguing that these patterns can be gradually changed, because they are acquired. 
Chesterman (1997, p. 5) has introduced the "Memes of Translation". The term "Meme" was first introduced by Richard Dawkins to the Sociology (Palumbo, 2009, p.75). Meme is the unit of cultural transmission, or imitation that transfers from a mind to another. In Translation Studies, Memes are transferred from one person to another through social interactions and they define the strategies and general discussions on translation. Chesterman considers such concepts as equivalence and translation norms and such binaries as "source vs. target," "free vs. literal translation," and "communicative vs. meaningful translation" as examples of memes which give orientation to translators in a particular community.

Touri (1995, pp.267-269) believes that translational behavior can be corrected and proposes some formula for that. He discusses two types of general laws in translation:

(1) The law of growing standardization

(2) The law of interference. The former states that in translation, the textemes in the source text transform to repertoremes in the target text (Touri, 1995, p.268). In other words, the textual relations of the source language (ex., uncommon collocations) are often mitigated and replaced by the more common relations in target language (ex., stereotypical collocations). The interference law also states that the characteristics of the source language are transferred into the target text and possibly results in a negative transfer that is deviations from the target language norms. These rules which have been proposed by Touri can be related with the concept of "universals of translation" that recently have drawn the attention of so many scholars.

\section{The position of translation pedagogy in the Holmes' map}

In Holmes' map of Translation Studies, teaching of translation falls under the category of applied translation studies. Wills considers translation training, criticism of translation, error analysis and the studies of the problems in the translation as the four important areas of applied science of translation (Wills, 1982).

As Touri (1995) points out this applied field is of a prescriptive nature which aims at determining the norms consciously (p.19).

\section{Process- oriented training of the translation}

Traditionally, at the academic level, the focus has been on product- oriented translation and the quality of translation products is mainly evaluated according to the degree of equivalence between the source and target texts, but most recently methodology of teaching translation has been shifted from product- oriented to process-oriented translation training (Palumbo, 2009, p.98).

Product- oriented education is mostly corpus-based (Palumbo, 2009, p.92) which aims to teach specific characteristics of target texts which are called "the universals of translation". Another objective of this type of education is to teach systematic patterns of language that are used by professional translators and are known as "translation techniques"(Palumbo, 2009, p.92). 
On the other hand, the process- oriented education is mostly related to mental activities and individual behaviors of translators and translation trainees during the act of translating (Palumbo, 2009, p.91).

This kind of education that is called "protocol- based" aims at describing the visible behaviors of professional translators during the translation process in deal with the problems of translation so the translation competence can be internalized in translation trainees (Palumbo, 2009, p.91).

Nevertheless process- oriented education is based on two perspectives: (1). internal perspective (2). exterior perspective (Palumbo, 2009, p.90); The internal perspective is related to mental and psychological processes involved in translation, while the external perspective focuses on the social aspects of translation in which many people (not only translators, but also publishers, commissioners, and the patronage) are somehow involved in translation process (Palumbo, 2009, p. 90 ) In the study of translation competence acquisition, both internal and external trends are combined and used alternatively.

\section{The concept of translation strategies}

The term "translation strategy" refers to general practices of textual transfer that are applied to longer segments of texts and lead the macro decisions made by translators (Chesterman, 1997, p.92). The opposite of it is "translation techniques" that are related to the micro level and which guide the decisions of the translators made in micro level. These techniques that are applied on shorter segments of texts, are referred to by so many terms like "transfer operations," "shifts," and "translation procedures" and are subject to various categories (Palumbo, 2009, p.132).

Each of the general methods of translation which are bipolar is associated with a specific strategy for translation (Palumbo, 2009, p.136). Translation strategies include:

Covert vs. Translation (House, 1997)

Semantic vs. communicative translation (Newark, 1981)

Documentary vs. Instrumental translation (Nord, 1997)

Foreignizing vs. domesticating translation (Venuti, 1992)

Free vs. Literal translation

\section{Translation Problems vs. Difficulties}

Translation is often described as the act of problem solving. Translational problems are referred to the aspects of the source text that don't have automated or internalized solutions and which require creativity. In Linguistic approach to translation, translation problems are defined as the differences in language (lexical, syntactic, and stylistic) between the source and target texts, but in the communicative approach to translation, the translation problem arises when the equivalence in functions between the source and target cannot be easily established and the problematic elements are related to cognitive considerations in 
transformation process (Palumbo, 2009, p. 129).

Nord (1997, p.64) has distinguished between two concepts of "translation problem" and "translation difficulty".

According to him, the problems of translation are objective and identifiable and of linguistic, cultural, cognitive and textual nature which doesn't result from the translator's lack of knowledge. On the other hand, the difficulties of translation are mental phenomena that are dependent on the individual translator (or translation trainee) and which result from the lack of competence in culture, language, and translation.

In other words, a particular text which seems difficult for novice translators can be quite easy for professional translators (Palumbo, 2009, p.36). For example, a novice translator may be concerned with finding "lexical equivalents", while the main concern for a professional translator is to find "functional equivalents".

\section{Translation errors}

Translation errors refer to the errors in the translated texts that result from the lack of translation competence, incorrect use of translation techniques, or strategies (Delisle, et al., 1999, p.89).

This concept which is mostly used in the evaluation of translation has a direct relationship with translation competence. Traditional categorization of translation errors has been based on categories like "incorrect meaning," "misinterpretation," and "interference." Despite facing criticism that goes back to 1970s, these categories that are based on the principles of comparative stylistics are still used in translator training (Waddington, 1999, p.37).

Traditional categorization is criticized on the grounds that instead of focusing on communicative aspects of translation, it focuses on the linguistic aspects of translation (Waddington, 1999, p.65).

Furthermore, due to the absence of communicative perspective, they cannot comment on a specific element of the target text in terms of the relevance to the aims of the target text, issues of cognition, or translation brief. Incorrect meaning refers to errors in which the target text element gains a meaning that is not usually associated with in the source language (Delisle et al., 1999, p.174). In addition, interference is considered as a phenomenon in which the decisions of the translator in the morphological, syntactic and lexical levels are affected by the arrangements in the source language (Palumbo, 2009, p.63). It can be said that in terms of style, interference can be considered as one the factors that leads to translationese. Misinterpretation refers to the errors that result from the misunderstanding of the terms related to culture-bound terms (Delisle et al., 1999, p.159).

The first attempt to evaluate translation errors from the function- oriented perspective can be traced back to Julian House who distinguished between covert and overt errors (Palumbo, 2009, p.81). The overt error occurs when the equivalence between the elements of the source and target text does not exist or grammatical deviation happens in the target language (Palumbo, 2009, p.81). 
On the other hand, covert errors occur when the elements in the target text cannot have equivalence with corresponding elements in the target text in terms of function. This type of error implies that the source and target text makes different expectations between different groups of audiences, so that no secondary function is added to the target text (Palumbo, 2009, p.28).

Other categories consider more subtle aspects. For example, Nord (1997, pp., 78-75) has made a distinction between textual, linguistic, cultural and cognitive errors. As a result of these distinctions, the translation quality is considered as a relative concept, that is, its measure is not based on absolute standards, but it is based on the relation with the goal of translation and any other aspect of the translation. Accordingly, it is said that errors are taken into account according to their relative importance in the overall context (Kussmaul, 1995, pp., 139-141).

Another popular categorization has been proposed by Pym (1992, p.282) who has made a distinction between binary and non-binary errors. Binary error, instead of a correct solution, gives an incorrect solution.

For example, linguistic or translational errors are binary errors. On the other hand, in the non-binary errors, target texts are put against other target texts that had a chance of being selected. In other words, non-binary errors are errors that make trainers give feedback like "it's true, but." Pym considers translation errors with a real meaning as an equivalent of nonbinary errors. Because he believes, translation competence is essentially equal with capability of selecting the most suitable solution among the possible solutions.

\section{Translation Techniques}

As mentioned, translation techniques are opposite translation strategies that lead the micro decisions made by translators and are often referred to as by various terms such as shifts, transfer operations, translation procedures (Palumbo, 2009, p. 134). Modulation, transpositions, and explicitation are examples of such translation techniques. Descriptions and different categorization have been made about translation shifts that are not explained here due to the limitations of the paper (Catford, 1965 \& Vinay \& Darbelnet, 1958, 1995).

Vinay and Darbelnet $(1995,1958)$ consider transpositions as "translation procedures" and divide them into two general categories of "direct" and "oblique." Direct methods include borrowing, calques, and literal translation, while oblique procedures include transposition, modulation, equivalence, and adaptation. Direct methods are based primarily on being literal. In cases where a literal translation does not fit, oblique procedures should be used.

\section{From prescriptivism to descriptivism}

From the 1970s onwards, the culture- oriented approaches in translation came to be known with the works of Israeli translation scholars known as "manipulation school" or "systematic approach" among whom a mention can be made of Itamar Even-Zohar, Gideon Toury, Teo Hermans, and Andre Lefevere. In these approaches, the translations are considered as the 
realities of the target culture. The implied meaning is that translation scholarship should be started from the target culture instead of the source culture.

Sometimes they are called with a general term like "target-oriented approaches". This represents a shift in theories from source-oriented approach toward product- oriented approach (Palumbo, 2009, p.35).

These approaches indicate that the limitation imposed on translation are not only of linguistic nature, but also include limitations of aesthetic, economic, cultural, and ideological nature in a way that from the cultural and historical perspectives, they discuss issues related to production, consumption and the impact of translations ( especially literary translations) in the societies. Researchers of these approaches have used theories that emphasize the function of social and cultural factors prevailing in the target culture. Scopus theory and functionalist approaches are the pioneers of these approaches. These approaches are related to the macro levels of translation education and unlike linguistic approaches, they are not of a prescriptive nature. Instead of accepting the existence of the norms of the transfer between languages, translation scholars interested in adopting this approach consider equivalent selection subject to cultural, social, and literary traditions. Since various factors are related to the target language and culture, the concept of equivalence has gradually been replaced the concept of norm (Palumbo, 2009, p.44).

\section{Conclusions}

Looking at the evolution of the translation theories, the pedagogical implications of these theories in translation courses can be understood. Before the Second World War, translation theories focused on the source and the theories mostly were related to micro level and emphasized the equivalence between the source and target languages. Therefore, they considered categorization of different equivalences, translation errors, and translation techniques. Some of them took advantage of the scientific methods in their studies (Willis, 1982). Then, they prescribed their findings to the translators. Despite criticism, the prescription mentioned in this article, is still central in translator- training centers and there is essentially no translation training possible without any prescription. In other words, the use of prescription is a necessity at the earlier stages of translation training and trainers should give feed back to the translations done by students according to the theories and prescribe the basic concepts of the translation to them. In the later stages, when students internalize the fundamental concepts of translation, the structure-oriented approaches can be replaced with post-structuralist approaches, and focus on the discussion can be changed from source-oriented to target-oriented translation. Although some trainers fear that the teaching of function-oriented (ex., Scopus theory) and target oriented theories in academic settings may set a bad example, because there will not be the principle of being faithful to the source. However, the fact is that these theories are indicative of the real nature of the translation in professional settings and our knowledge of them is considered as part of our translation competence. And essentially the true competence is created when the translation trainees become familiar with both theories of structuralism and poststructuralism and both micro and macro levels. Therefore, translation trainers need to pay attention to both levels and take both 
levels into consideration in developing training materials in which case the students' translation quality will be much better.

\section{References}

Catford, J. C (1965). A Linguistic theory of translation. London: Oxford University Press.

Chesterman, A. (1997). Memes of translation: The spread of ideas in translation theory. Amsterdam / Philadelphia: Benjamins. http://dx.doi.org/10.1075/bt1.22

Delisle, J., Lee-Janke, H. Cormier, M.C. (eds) (1999). Terminologie de la traduction / Translation Terminology/ Terminologia de la traducción/ Termnologie der Übersetzung. Amsterdam/Philadelphia: Benjamins. http://dx.doi.org/10.1075/fit.1

Halverson, S. (1997). The concept of equivalence in translation: Much ado about something. Target, 9(2), 207-233. http://dx.doi.org/10.1075/target.9.2.02hal

Harris, B. (1977). The importance of natural translation. Working Papers on Bilingualism, 12, 96-114.

House, J. (1977). A model for translation quality assessment. Tübingen:Narr

Kussmaul, p. (1995). Training the translator. Amsterdam / Philadelphia: Benjamins. http://dx.doi.org/10.1075/btl.10

Newmark, P. (1981). Approaches to translation. Oxford: Pergamon.

Nord, C. (1997). Translating as a purposeful activity: Functionalist approaches explained. Manchester: St Jerome.

PACTE (2005). Investigating translation competence: Conceptual and methodological issues. Meta, 50(2), 609-619. http://dx.doi.org/10.7202/011004ar

Palumbo, G. (2009). Key terms in translation studies. London / New York: Continuum.

Pym, A. (1992). Translation error analysis and the interface with Language teaching. In C. Dollerup \& A.loddegaard (eds.), Teaching translation and interpreting (pp.279-288). Amsterdam / Philadelphia: Benjamins.

Pym, A. (2003). Redefining translation competence in an electronic age: In defense of a minimalistic approach. Meta, 48(4), 481-492. http://dx.doi.org/10.7202/008533ar

Schaffner, C., \& Adab, B. (eds.) (2000). Developing translation competence. Amsterdam / Philadelphia: Benjamins. http://dx.doi.org/10.1075/btl.38

Simeoni, D. (1998). The pivotal status of the translator's Habitus. Target, 10(1), 1-39. http://dx.doi.org/10.1075/target.10.1.02sim

Snell-Honby, M. (2006). The turns of translation studies. Amsterdam / Philadelphia: Benjamins. http://dx.doi.org/10.1075/btl.66

Toury, G. (1995). Descriptive translation studies and beyond. Amsterdam / Philadelphia: 
Benjamins. http://dx.doi.org/10.1075/btl.4

Toury, G. (1999). A handful of paragraphs on "translation" and "norms". In C. Schäffner (ed.), Translation and norms (pp. 9-31). Clevedon: Multilingual Matters.

Venuti, L. (ed.) (1992). Rethinking translation, discourse, subjectivity, and ideology. Londin/New York: Routledge.

Vinay, J. and Darbelnet, J. (1958/1995), Comparative stylistics of French and English: A methodology, translated and edited by Sager, j. and Hamel, M. Amsterdam / Philadelphia: Benjamins.

Waddington, C. (1999). Estudio comparativo de diferentes métodos de evaluación de traducción general (Inglés-Español). Madrid: Universidad Pontificia Comillas.

Wills, w. (1982). The science of translation, problems and methods. Tubingen: Narr. 